3. Отчет по научно-исследовательской работе разработка схемы и программы развития электроэнергетики республики саха (якутия) на 2014-2018 гг.

4. «Переток». Возобновляемая Арктика. [Электронный ресурс]. URL: http://peretok.ru/articles/strategy/15052/ЭКОНОМИКА И УПРАВЛЕНИЕ.

5. Возобновляемые источники энергии Якутии. [Электронный ресурс]. URL: http://yakutiaprime.ru/innovatsii/7075.

6. Возобновляемая энергия. [Электронный pecypc]. URL: http://www.energosovet.ru/bul_stat.php?idd=210.

7. Выбросы парниковых газов в Европе требуют снижения. [Электронный ресурс]. URL: http://ecobeing.ru/news/2015/europe-greenhouse-gases-minimum/.

8. Возобновляемая энергетика. И. Ядрошиников. Успехи ВИЭ в мире и попытки развития в России. [Электронный ресурс]. URL: http://bellona.ru/2016/11/09/bellonaconference-renewable/.

\title{
Способы повышения пропускной способности линий электропередачи
}

\section{Тимофеева А.В., аспирант, Северо-Восточный федеральный университет, 2. Якутск \\ E-mail: mariya timo@mail.ru}

Научный руководитель: д.m.н., профессор Бурянина Н.С.

Электрификация и развитие сети железнодорожного транспорта, освоение новых месторождений и производств в Сибири и на Дальнем Востоке, развитие систем накопления электроэнергии для малых потребителей, а также развитие других отраслей народного хозяйства приводит к росту энергопотребления в России.

В основе управления электросетевым комплексом России лежит «Энергетическая стратегия России на период до 2030 года», которая направлена на максимально эффективное использование природных энергетических ресурсов и потенциала энергетического сектора для устойчивого роста экономики, повышения качества жизни населения страны и содействия укреплению её внешнеэкономических позиций. Одной из важнейших составляющих решения этой сложной комплексной задачи является повышение энергетической эффективности электросетевого комплекса [1].

В настоящее время государственная политика в области энергетики, во многом определяющей развитие всех отраслей промышленности, направлена на увеличение мощности электрических станций, пропускной способности электрических сетей и эффективности использования энергоресурсов [2]. Передача больших количеств энергии производится по высоковольтным линиям, в дальнейшем речь идет именно о таких линиях. На сегодняшний день существует множество способов повышения мощности передаваемой линии, каждый из которых имеет свои достоинства и недостатки.

Основные возможности повышения мощности передаваемой линии:

- $\quad$ Строительство новой линии

- $\quad$ П Повышение класса напряжения 
- $\quad$ Повышение сечения или применение новых высокопрочных материалов для проводов

- $\quad$ Установка компенсирующих устройств

- $\quad$ Расщепление фаз на несколько проводов

- $\quad$ Сближение фаз

Возможности прокладки новых линий ограничиваются экономическими и социальными аспектам - увеличением стоимости земли под трассы линий, потребностью электроснабжения городов и крупных предприятий $\mathrm{c}$ плотной застройкой и высокими требованиями к безопасности населения [3].

Повышение номинального напряжения и сечения провода с целью повышения пропускной способности линий электропередачи связано с дополнительными затратами, необходимыми на изоляцию, опоры и электрооборудование подстанций. По условиям экологии окружающей среды не всегда возможно осуществить перевод воздушной линии электропередачи на более высокое напряжение.

А стоимость различных высокотехнологичных проводов на сегодняшний день в 5 раз превышает стоимость обычного провода.

Применение устройств компенсации на воздушных линиях электропередачи является более эффективным способом повышения пропускной способности, но для высоковольтных электропередач требует дополнительных сложных установок и надежной эксплуатации и обслуживания их.

Расщепление фаз на несколько проводов ведет к уменьшению индуктивного и волнового сопротивлений, также к увеличению емкости и натуральной мощности линий электропередачи. Однако и этот способ имеет те же недостатки, что и предыдущие.

Наиболее приемлемый по этим соображениям вариант - повышение пропускной способности существующих линий электропередачи. Эта задача решается как улучшением использования линий - повышением рабочих напряжений, нагрузок на провода, так и применением дополнительных технических средств - компенсаторов реактивной мощности, или изменением конструкции линии.

Повышение пропускной способности по любому заданному сколь угодно большому пределу передаваемой мощности достигается двумя основными путями: снижением продольного индуктивного сопротивления фаз линии и увеличением поперечной емкостной проводимости.

На основании исследований и анализа влияющих факторов можно применить комбинированный способ повышения пропускной способности линий электропередачи. Например, одновременное расщепление и сближение фаз позволяет более эффективно повышать передаваемую мощность по сравнению с предыдущими способами.

Пропорциональная зависимость радиуса расщепления фазы $r_{p}$ и междуфазного расстояния $D_{0}$ определяет целесообразность значительного сокращения междуфазовых расстояний, что оказывается возможным при увеличении числа проводов в фазе [4].

Предлагается новое конструктивное исполнение линии с разновысотной подвеской, где два проводника, состоящие из одного или нескольких расщепленных проводов подвешиваются на опорах линии электропередачи на разной высоте, причем нижний проводник кроме крепления на опорах крепится к верхнему проводнику так, что стрела его провеса получается меньше стрелы провеса верхнего проводника. Таким образом, расстояние между проводниками изменяется от минимального в середине 
пролета до стрелы провеса на опоре. Тем самым, увеличивается эквивалентный радиус провода фазы, приводящий к существенному снижению индуктивного сопротивления и увеличению емкостной проводимости. Кроме того, появляется возможность сближения фаз, так как уменьшается амплитуда раскачивания проводов. В пределе, когда нижний проводник натягивается горизонтально, раскачивание фаз исключено полностью.

Экологические риски, связанные с возможным негативным воздействием на окружающую среду, минимизируются благодаря сближению фаз, т.е. уменьшением отчуждаемых земельных угодий под трассы линии. Предложенное инновационное технологическое решение позволяет существенно увеличить пропускную способность, уменьшить эксплуатационные затраты и способствует минимизации негативного воздействия на окружающую среду.

\title{
Список литературы:
}

1. Программа инновационного развития ПАО «ФСК ЕЭС» на 2016-2020 годы с перспективой до 2025 года, 89 стр, 3.3. Энергоэффективность и снижение потерь, краткое описание проекта

2. Александров Г.Н. Передача электрической энергии / Г.Н. Александров. - 2-е изд.- СПб.: Изд-во Политехн. ун-та, 2009.- 412 с. (Энергетика в политехническом университете)

3. Алексеев Б.А. Повышение пропускной способности воздушных линий электропередачи и применение проводов новых марок// // Производственно-научный технический журнал «Электро» - 2009. - № 3. - С-51.-53.

4. Максимов А.В., Паули В.К., Бычкова М.П., Воротников Р.А. Компенсация реактивной мощности - актуальная задача энергосбережения // Производственнонаучный технический журнал «Электро» - 2009. - № 3. - С-7.

\section{Повышение эффективности функционирования горного предприятия на оптовом рынке электроэнергии путем регулирования электрической нагрузки}

\author{
Четвертаков Т.Д., студент, \\ Технический институт (филиал) \\ Северо-Восточного федерального университета, г. Нерюнгри \\ E-mail: tima.chetvertakov@mail.ru
}

Научный руководитель: к.т.н. доцент Антоненков Д.В.

Актуальность поставленной для решения технической задачи

График электрической нагрузки любого предприятия представляет собой кривую, где имеются часы максимума и минимума нагрузки. Чем больше разница между плановым и фактическим режимами работы (неравномерность), тем дороже обходится электрическая энергия. Так как при повышении этой разницы, устанавливается надбавка к тарифам на электроэнергию или происходит начисление штрафов предприятию.

Тема является актуальной, так создание эффективной регулировочной нагрузки, может увеличить производительность карьерных экскаваторов, улучшив тем самым 